\title{
Infeção Aguda pelo Vírus da Imunodeficiência Humana 1: uma janela de oportunidade
}

\author{
Acute infection by Human Immunodeficiency Virus 1: an opportunity time
}

\author{
Eunice Oliveira, Sofia Marques Santos, Maria Manuela Soares, Francisco Silva. \\ Serviço de Medicina 2 do Hospital de Egas Moniz. Centro Hospitalar de Lisboa Ocidental.
}

\begin{abstract}
Resumo
A infeção aguda pelo Vírus da Imunodeficiência Humana $1(\mathrm{VIH}-1)$ constitui um desafio, sendo crucial um elevado índice de suspeição clínica para se alcançar o diagnóstico, sobretudo na ausência de contexto epidemiológico aparentemente relevante. Os autores descrevem 0 caso de uma mulher de 52 anos internada por um quadro clínico sugestivo de mononucleose infeciosa associada a náuseas, vómitos e diarreia com uma semana de evolução. A doente negava atividade sexual, consumo de drogas injetáveis ou transfusões sanguíneas. Objetivamente salientava-se a presença de febre elevada, lesões ulceradas da cavidade oral, hiperemia da faringe, exantema maculopapular e adenopatias cervicais bilaterais. Os exames laboratoriais evidenciavam bicitopénia, padrão hepático de citocolestase, aumento da lactato desidrogenase e da lipase, tendo-se concluído após investigação etiológica por Infeção aguda pelo VIH-1 com Pancreatite aguda nesse contexto. Após início da terapêutica antiretroviral verificou-se resolução completa do quadro clínico. Assim, pretende-se ilustrar a necessidade da consideração da síndrome retroviral aguda no diagnóstico diferencial da síndrome mononucleósica, salientando a relevância dos testes de $4^{\mathrm{a}}$ geração, bem como o papel da terapêutica antiretroviral na infeção aguda. Palabras clave: Virus de Inmunodeficiencia Humana 1.

Síndrome mononucleosico.
\end{abstract}

\section{Introdução}

A infeção aguda pelo VIH-1 (vírus da Imunodeficiência Humana 1) corresponde à fase imediatamente após o contágio pelo vírus, sendo definida atualmente pela presença do antigénio p24 (Ag p24) e/ou do RNA do VIH-1 no plasma, com anticorpos anti $\mathrm{VIH}-1$ indetetáveis ${ }^{1,2}$. Este período decorre geralmente nas primeiras 2 a 6 semanas após a exposição ao vírus. 0 surgimento dos ensaios imunoenzimáticos de $4^{\mathrm{a}}$ geração permitiu a deteção em simultâneo de anticorpos anti VIH-1/NIH-2 e do antigénio p24 (Ag p24), com subsequente encurtamento do período de janela da infeção e assim aumento da sensibilidade e especificidade diagnóstica. A fase da infeção aguda pelo VIH-1 caracteriza-se pela sua elevada contagiosidade em sequência da explosão da virémia que se verifica nesse período, podendo apresentar um amplo espetro clínico, desde doentes assintomáticos até quadros clínicos típicos e ainda outros menos frequentes ${ }^{3}$. Assim, os doentes são sintomáticos em 40 a 90\% dos casos ${ }^{1}$, manifestando-se a maioria com quadro mononucleose-like, com febre, adenopatias, faringite, rash cutâneo, mialgias, artralgias e cefaleias ${ }^{3-5}$. Esta constelação de sintomas é denominada por síndrome retroviral aguda, sendo contudo comum a outras entidades clínicas, nomeadamente em diversas infeções víricas. Assim, a inespecificidade do quadro

\begin{abstract}
The diagnosis of acute infection by the Human Immunodeficiency Virus 1 (HIV-1) is a challenge, being essential a high degree of suspicion to achieve the diagnosis, particularly in the absence of an apparent epidemiological context. The authors present a case of a 52 years old woman with a clinical picture suggestive of infectious mononucleosis, associated with nausea, vomiting and diarrhea with one week of evolution. The patient denied sexual activity, injection drug use or blood transfusions. Physical examination pointed out the presence of prostration, ulcerative lesions of the oral cavity, sore throat, maculopapular rash and bilateral cervical lymphadenopathies. Laboratory studies showed bicytopenia, citocolestase pattern, increased lactate dehydrogenase and lipase. After etiological investigation it was assumed the diagnosis of acute HIV-1 infection with acute pancreatitis in this context. After the beginning of the antiretroviral therapy there was complete resolution of symptoms. The authors pretend to show that acute retroviral syndrome should be considered in the differential diagnosis of mononucleosis like syndrome, the relevance of $4^{\text {th }}$ generation tests as well as the role of antiretroviral therapy in the acute infection.
\end{abstract}

Keywords: Human Immunodeficiency Virus 1.

Mononucleosis like syndrome.

clínico e o seu carácter maioritariamente autolimitado, contribuem para a dificuldade em se alcançar o diagnóstico na fase aguda da infeção.

\section{Caso clínico}

Doente do sexo feminino de 52 anos de idade, leucodérmica, portuguesa, cabeleireira e viúva. Dos antecedentes pessoais salientava-se tabagismo ativo (20UMA), gastrite crónica, nódulo benigno da mama esquerda excisado 4 meses antes e fratura radial esquerda há 3 meses. Automedicava-se intermitentemente com Omeprazol 20mg. Negava outros hábitos medicamentosos, assim como hábitos toxicofílicos ou alergias medicamentosas conhecidas. Plano nacional de vacinação atualizado.

A doente foi internada através do Serviço de urgência (SU) para esclarecimento de quadro clinico com uma semana de evolução caracterizado por anorexia, perda ponderal $(<10 \%$ peso corporal prévio), náuseas, vómitos pós-prandiais e febre com calafrio (temperatura timpânica máxima de $39,6^{\circ} \mathrm{C}$ ) que cedia parcialmente ao paracetamol. Referia também gengivorragias, lesões cutâneas maculopapulares no tronco e pescoço, não pruriginosas e lombalgia bilateral com irradiação aos flancos, tipo moinha, que agravava com a mobilização e sem factores de alivio. Negava outra sintomatologia, nomeadamente cefaleias, dor abdominal, sintomas respiratórios ou génito-urinários. Aparentemente sem contexto epidemiológico de relevo, negando além dos acima referidos, consumo 
de produtos lácteos não pasteurizados ou água não potável, assim como traumatismos, transfusões sanguíneas, relações sexuais no último ano, contacto com pessoas doentes ou viagens a áreas endémicas. Tinha 2 cães saudáveis e vacinados.

Ao exame objetivo a doente estava prostrada mas colaborante e orientada. Sem défices focais, rigidez da nuca ou sinais meníngeos. Tensão arterial de 110/67mmHg, frequência cardíaca de 91bpm, saturação periférica 95\% em ar ambiente, temperatura timpânica de $37.7^{\circ} \mathrm{C}$. Palidez cutânea moderada e exantema eritematoso maculopapular, não pruriginoso, na região do pescoço, tronco e membros superiores (poupando as plantas). Orofaringe hiperemiada com lesões ulceradas no palato mole, eritematosas, de fundo nacarado com periodontite e halitose exuberante associadas, bem como gengivorragias autolimitadas. Adenopatias cervicais bilaterais $(1 \mathrm{~cm})$, móveis, não aderentes, dolorosas. Avaliação cardiopulmonar inalterada. Abdómen ligeiramente doloroso à palpação do hipocôndrio direito, sem organomegalias, massas anómalas, sinais de reação peritoneal, Murphy vesicular ou renal, com ruídos hidroaéreos presentes. Membros inferiores sem edemas ou sinais inflamatórios. Analiticamente salientava-se bicitopénia, elevação das transaminases, da LDH (lactato desidrogenase) e da lipase (Tabela 1). Restantes exames complementares de diagnóstico inalterados (radiografia torácica e abdominal; ecografia abdominopélvica e renal; electrocardiograma).

Durante o internamento foram pedidas serologias, donde se destacava cicatriz imunológica de Citomegalovírus (CMV) e Epstein-Barr vírus (EBV), assim como positividade do teste de $4^{\mathrm{a}}$ geração $\mathrm{Ac}$ anti-VIH1/2 e Ag p24, com restantes serologias negativas (Tabela 2). No sentido da caracterização da infeção VIH foi realizado estudo adicional, que revelou: perfil de Ac anti-VIH 1/2 (sgp120, gp41, sgp105, gp36, p31, p24, p17) negativo, sugerindo-se pesquisa do RNA do VIH 1/2; teste de diferenciação VIH-1/NIH-2 inconclusivo; Western Blot VIH-1 não realizado perante resultado do teste de diferenciação; carga viral VIH-1 superior a 10.000.000cópias/ml; teste de resistência do VIH-1 aos antiretrovirais negativo.

A quantificação das sub-populações linfocitárias em sangue periférico revelou 493 linfócitos totais/uL com 96 (19\%) linfócitosT CD4+ul (valor referência: 410-1590 cél/ul /31-60\%) com uma relação $\mathrm{CD}^{+}$/ CD8+ de 0.53 .
Assim, concluiu-se por Infeção VIH aguda, tendo sido repetidos ao fim de uma semana os seguintes parâmetros: Western Blot VIH-1 positivo; teste de diferenciação HIV-1/HIV-2 positivo para VIH-1. Os exames microbiológicos diretos e culturais (sangue e urina) foram negativos. Dada a elevação persistente e gradual da lipase durante 0 internamento (Tabela 1) assumiu-se o diagnóstico de Pancreatite aguda no contexto da síndrome retroviral aguda. A Tomografia computorizada toracoabdominopélvica excluiu adenopatias mediastinicas ou abdomino-pélvicas, assim como alterações pancreáticas. Confrontada com estes factos, a doente revelou ter ocorrido relação sexual esporádica cerca de 1 mês antes. Foi instituída terapêutica com tenofovir e emtricitabina+darunavir/ritonavir, tendo a doente alta ao $7^{\circ} \mathrm{dia}$ de terapêutica antiretroviral, com melhoria sintomatológica e analítica (Tabela 1). Tem-se verificado boa adesão à terapêutica, com seguimento regular em consulta de Infeciologia, mantendo cargas virais indetetáveis, sem efeitos secundários aos antiretrovirais ou infeções oportunistas documentadas.

\section{Discussão}

0 caso clínico apresentado corresponde a uma das formas de apresentação típica da infeção aguda pelo VIH-1, a síndrome mononucleósica, com febre, odinofagia e linfadenopatias ${ }^{3-5}$. Apesar de ser frequente nos doentes com infeção aguda sintomática, este quadro não é específico da infeção pelo VIH-1, daí a necessidade de realizar o diagnóstico diferencial com outras entidades clínicas, nomeadamente com infeção a EBV, CMV, outras hepatites virais, toxoplasmose, rubéola, sífilis e doenças auto-imunes como o Lúpus Eritematoso Sistémico. Não obstante a inespecificidade dos sintomas, a presença de úlceras mucocutâneas dolorosas e o facto do quadro clínico ter uma semana de evolução são a favor de infeção aguda pelo VIH-1. 0 rash cutâneo maculopapular é também um achado frequente na forma precoce desta patologia, caracterizando-se por apresentar uma coloração rosácea, ser não pruriginoso e de contornos bem delimitados; no entanto, não costuma poupar plantas nem palmas, sendo mais frequente

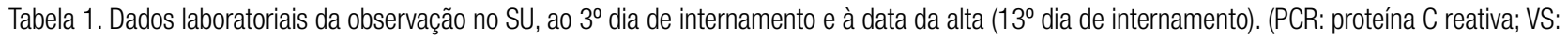
velocidade de sedimentação; AST: aspartato aminotransferase; ALT: alanina aminotransferase; GGT: gamaglutamiltranspeptidase; FA: fosfatase alcalina; LDH: lactato desidrogenase; ECA: enzima conversora da angiotensiva; ANA's: anticorpos anti-nucleares, que incluem anticorpos anti-Ro; anti-La, antiSM, anti-nRNP, anti-Scl-70, anti-J01; * Raros agregados plaquetários; anisocitose; ${ }^{\star *}$ Presença de linfócitos ativados; ${ }^{\star \star \star}$ Perfil eletroforético inalterado)

\begin{tabular}{|l|c|c|c|c|}
\hline Parâmetros analíticos & Valor referência & SU & Internamento & Alta \\
\hline Hemoglobina (g/dl) & $12.0-15.0$ & 15.1 & 12.6 & 13.9 \\
\hline Leucócitos (x109/L) & $4.0-10.0$ & 3.7 & 2.7 & 7.1 \\
Neutróf / Linfócit (\%) & $40-80 / 20-40$ & $69.9 / 22.2^{\star *}$ & $72.6 / 18.2^{\star *}$ & $39.1 / 49.0$ \\
\hline Plaquetas (x 109/L) & $150-400$ & $71^{*}$ & $75^{*}$ & 350 \\
\hline Tempo Protrombina (seg) & $<14$ & 10.2 & 10.2 & \\
\hline PCR (mg/dl) & $<0.5$ & 0.30 & 3.10 & 2.20 \\
\hline VS (mm/h) & $<20$ & & 26 & $63 / 123$ \\
\hline AST/ALT (U/L) & $14-36 / 09-52$ & $305 / 260$ & $235 / 232$ & $320 / 98$ \\
\hline GGT/ FA (U/L) & $12.0-43.0 / 25-100$ & & $395 / 108$ & 0.70 \\
\hline Bilirrubina total (mg/dL) & $<1.30$ & 0.32 & 0.50 & 636 \\
\hline Lipase (U/L) & $73-393$ & 442 & 900 & 877 \\
\hline LDH (U/L) & $313-618$ & 1200 & 1449 & \\
\hline Proteinas totais/ Albumina (g/dl) & $6.2-.8 .6 / 3.5-5.0$ & $7.0 / 3.1$ & $5.4^{\star * *} / 2.5$ & \\
\hline
\end{tabular}


na região superior do tronco e face mas atingindo também 0 couro cabeludo e as extremidades ${ }^{6}$.

Dado que 0 trato gastrointestinal é um dos alvos principais da replicação vírica durante a infeção aguda pelo VIH-1, sintomas como náuseas, vómitos anorexia, diarreia e perda ponderal são frequentes, no entanto, outras manifestações mais sérias como a pancreatite aguda e a hepatite são raras. Com efeito, parece existir uma associação entre a depleção de células CD4 e o surgimento de pancreatite aguda, o que explicará a situação clínica apresentada ${ }^{7}$.

0 diagnóstico da infeção $\mathrm{VIH}$ em fase precoce permite 0 controlo da replicação vírica, a preservação do sistema imune e a diminuição da gravidade da infeção aguda, além de diminuir o risco de transmissão e de mutação vírica, estando atualmente recomendado 0 tratamento antiretroviral a todos os doentes com infeção pelo VIH-1, nomeadamente na infeção aguda ${ }^{1,8}$, com 0 objetivo de suprimir a carga de RNA viral para níveis indetetáveis ${ }^{1}$.

Como demonstrado no caso clínico em análise, é possível atualmente a deteção da infeção em fases muito precoces com os testes imunoenzimáticos de $4^{\mathrm{a}}$ geração, nomeadamente no período em que ainda não são detetáveis os anticorpos anti VIH-1, apenas pela presença do Ag p24 (infeção aguda). A positividade nestes testes carece da validação do diagnóstico com os testes confirmatórios (Western Blot e mais recentemente 0 teste de diferenciação $\mathrm{VIH}-1 / \mathrm{NIH}-2$ ) e quantificação do RNA viral ${ }^{1,2}$, estando recomendada a repetição dos anticorpos anti VIH-1 uma semana após o diagnóstico, a fim de documentar a seroconversão e mesmo do teste de diferenciação se o primeiro tiver sido inconclusivo². Na infeção aguda pelo VIH-1 é comum a existência de cargas virais muito elevadas, geralmente superiores a 100.000 cópias/mL ${ }^{4,14}$, que tendem a diminuir ao fim de 2 meses. Está indicada a realização do teste de resistência aos antirretrovirais antes do início da terapêutica, não devendo este no entanto atrasar a instituição da mesma.

A infeção aguda pelo VIH-1 cursa com alterações analíticas sobreponíveis a outros processos infeciosos, como a elevação da enzimologia hepática, anemia moderada, trombocitopénia e numa fase muito precoce leucopénia, com recuperação posterior devido à expansão linfocitária, em que se verifica uma inversão da razão normal de $\mathrm{CD} 4^{+} / \mathrm{CD} 8^{+}$para $<1$, devido à proliferação mais rápida de $\mathrm{CD}^{+}$que de $\mathrm{CD} 4^{+}$ 9,10. No caso clínico apresentado apenas estava ausente a anemia, estando presentes as restantes alterações, nomeadamente uma razão $\mathrm{CD4}^{+} / \mathrm{CD} 8^{+}$de 0.53 . A presença de linfócitos atípicos é frequente após a fase de recuperação leucocitária, no entanto é substancialmente menor do que na síndrome mononucleósica causado pelo EBV. Nalguns casos de infeção aguda pelo VIH-1 a pesquisa de anticorpos heterófilos da mononucleose é positiva, no entanto, este resultado não exclui o diagnostico de infecção aguda pelo VIH-1, não sendo claro ainda se representa um resultado falso positivo ou uma reativação do EBV durante a infeção pelo $\mathrm{VIH}-1^{11-13}$.
Assim, pretendemos salientar que o diagnóstico da infeção aguda pelo $\mathrm{VIH}-1$ carece de elevada suspeição clínica, pois a constelação de sinais e sintomas é sobreponível a outras entidades nosológicas, mas atualmente é possível em fases cada vez mais precoces da infeção, permitindo o início imediato de terapêutica e o controlo da progressão da doença.

Tabela 2. Serologias investigadas

\begin{tabular}{|l|c|}
\hline Parâmetros analíticos & Resultado \\
\hline CMV, Ac IgG & Positivo \\
\hline CMV, Ac IgM & Negativo \\
\hline EBV, Ac anti EBNA IgG & Positivo \\
\hline EBV, Ac anti VCA IgG & Positivo \\
\hline EBV, Ac anti VCA IgM & Negativo \\
\hline Hepatite A, Ac IgM & Negativo \\
\hline Hepatite B, Ag HBs & Negativo \\
\hline Hepatite B, Ac HBc & Negativo \\
\hline Hepatite C, Ac anti-VHC & Negativo \\
\hline Ac. heterófilos da Mononucleose & Negativo \\
\hline Ac. anti-VIH 1/2 e Ag p24 VIH & Positivo \\
\hline Ac. anti-Treponema pallidum & Negativo \\
\hline Ac. IgG anti-Toxoplasma gondii & Negativo \\
\hline Ac. IgM anti-Toxoplasma gondii & Negativo \\
\hline Ac. anti-Brucela (Rosa de Bengala) & Negativo \\
\hline
\end{tabular}

\section{Bibliografia}

1. Panel on Antiretroviral Guidelines for Adults and Adolescents. Guidelines for the Use of Antiretroviral Agents in HIV-1-Infected Adults and Adolescent. Department of Health and Human Services. Available at http://www.aidsinfo.nih.gov/ContentFiles/AdultandAdolescentGL.pdf. (acesso a 1 Novembro 2015).

2. European AIDS Clinical Society. Guidelines 8.0. October 2015.

3. Braun DL, Kouyos RD, Balmer B, Grube C, Weber R, et al. Frequency and Spectrum of Unexpected Clinical Manifestations of Primary HIV-1 Infection. Clin Infect Dis 2015; 61:1013.

4. Daar ES, Little S, Pitt J, Santangelo J, Ho P, et al. Diagnosis of primary HIV-1 infection. Los Angeles County Primary HIV Infectionv Recruitment Network. Ann Intern Med. 2001; 134(1):25-29.

5. Kared H, Lelièvre JD, Donkova-Petrini V, Aouba A, Melica G, et al. HIV-specific regulatory T cells are associated with higher CD4 cell counts in primary infection. AIDS 2008; 22:2451.

6. Lapins J, Gaines H, Lindback S, Lidbrink P, Emtestam L. Skin and mucosal characteristics of symptomatic primary HIV-1 infection. AIDS Patient Care STDS 1997; 11-67.

7. Dragovic G. Acute pancreatitis in HIV/AIDS patients: an issue of concern. Asian Pac J Trop Biomed 2013; 3(6): 422-425

8. Ludgren JD, Babiker AG, Gordin F, Emery S, Grund B, et al (INSIGHT START Study Group). Initiation of Antiretroviral therapy in Early Asymptomatic HIV infection. NEJM 2015 Aug 27; 373(9):795-807.

9. Centers for Disease Control and prevention (CDC). Detection of acute HIV infection in two evaluations of a new HIV diagnostic testing algorithm- United States, 2011-2013. MMWR Morb Mortal Wkly Rep 2013; 62:489.

10. Cooper DA, Tindall B, Wilson EJ, Imrie AA, Penny R. Characterization of t Iymphocyte responses during primary infection with human immunodeficiency vírus. J Infec Dis 1988; 157:889

11. Tindall B, Cooper DA. Primary HIV infection: host responses and intervention strategies. AIDS 1991; 5:1

12. de Jong MD, Hulsebosch HJ, Lange JM. Clinical, virological and immunological features of primary HIV-1 infection. Genitourin Med 1991; 67:367

13. Vidrih JA, Walensky RP, Sax PE, Freedberg KA. Positive Epstein-Barr vírus heterophile antibody tests in patientes with primary human immunodeficiency vírus infection. Am J Med 2001;111:192

14. Hecht FM, Busch MP, Rawal B, Webb M, Rosenberg E, et al. Use of laboratory tests and clinical symptoms for identification of primary HIV infection. AIDS.2002; 16 (8): 1119-1129. 